\title{
Huaier Extract Inhibits Breast Cancer Progression Through a LncRNA-H19/MiR- 675-5p Pathway
}

\author{
Jijun Wang ${ }^{\mathrm{a}}$ Xiaolong Wang ${ }^{\mathrm{a}} \quad$ Tong Chen $^{\mathrm{b}} \quad$ Liyu Jiang $^{\mathrm{a}} \quad$ Qifeng Yang $^{\mathrm{a}, \mathrm{c}}$ \\ aDepartment of Breast Surgery, Qilu Hospital, Shandong University, Jinan, Shandong, bSchool of \\ Medicine, Shandong University, Jinan, Shandong, 'Department of Pathology Tissue Bank, Qilu Hospital, \\ Shandong University, Jinan, Shandong, P.R. China
}

\author{
Key Words \\ Huaier • H19 • MiR-675-5p • CBL • Breast cancer
}

\begin{abstract}
Background/Aims: Increasing evidence indicates that Huaier extract has promising therapeutic effects against cancer. However, the mechanisms that underlie its anti-tumor effects remain unclear. In recent years, various studies have shown that long noncoding RNAs (IncRNAs) play a critical role in the regulation of cancer development and progression. Here, we explored the role of IncRNAs in Huaier-induced tumor suppression. Methods: Microarray profiling was performed to identify the candidate IncRNAs affected by Huaier extract. Quantitative realtime PCR ( $q P C R$ ) was used to evaluate the transfection efficiency and the influence of Huaier extract on H19 expression. The effect of Huaier extract on the cell viability was examined by MTT. Moreover, the rates of apoptotic cells were detected using flow-cytometric analysis. Western blot analysis was applied to show the protein levels of CBL. Results: Microarray data derived from Huaier-treated breast cancer cells identified H19 as a potential target. Huaier extract reduced the expression of H19. The over-expression of $\mathrm{H} 19$ inhibited the cytotoxic effects of Huaier extract; in contrast, reduced $\mathrm{H} 19$ expression enhanced the function of Huaier extract. MiR-675-5p was identified as a mature product of H19. Moreover, Huaier extract reduced the miR-675-5p expression. Upregulating miR-675-5p reversed the inhibitory effects of Huaier extract, whereas downregulating miR-675-5p sensitized breast cancer cells to the effect of Huaier extract. In addition, Huaier extract increased the expression of CBL protein, a direct target of miR-675-5p. Conclusion: Collectively, the data demonstrate that Huaier extract reduces viability and induces apoptosis in breast cancer cells via $\mathrm{H} 19-\mathrm{miR}-675-5 \mathrm{p}-\mathrm{CBL}$ axis regulation.

(C) 2017 The Author(s)

Published by S. Karger AG, Basel
\end{abstract}

\section{Introduction}

Breast cancer is the most common cancer worldwide and the leading cause of cancerrelated mortality among women [1]. Among the various therapies available, TCM (Traditional 
Chinese Medicine) has an important role [2, 3]. Huaier extract, which has been used in China for approximately 1600 years [4], has attracted increasing attention as a result of its antitumor activity $[5,6]$. Studies show that Huaier extract acts as a tumor suppressor by inhibiting tumor growth [7] and metastasis [8]; and preventing resistance to chemotherapy [9]. Our previous studies indicate that Huaier extract inhibits breast cancer progression by inducing apoptosis and autophagy, inhibiting angiogenesis, modulating the ER $\alpha$ pathway, targeting cancer stem cells, and regulating tumor-associated macrophages [4, 10-14]. However, the mechanisms that underlie these effects are unclear.

Noncoding RNAs (ncRNAs) are RNA molecules that do not encode proteins. Recent reports suggest that ncRNAs play critical roles in cancer development and progression $[15,16]$. Long noncoding RNAs (lncRNAs) are ncRNAs longer than 200 nucleotides [17]. Accumulating evidence indicates that IncRNAs regulate breast cancer development and progression via multiple pathways [18-20]. LncRNA H19 is encoded by a paternally imprinted gene, H19, whose oncogenic functions have been investigated in the context of pancreatic ductal adenocarcinoma, hepatocarcinoma, bladder cancer, glioma and gastric cancer [2125]. Recent data and studies of miR-675-5p derived from lncRNA H19 indicate that the IncRNA H19/miR-675-5p axis plays a pro-oncologic role by regulating the expression of several target genes [26-30].

Here, we examined the roles of H19 and miR-675-5p in the anti-tumor effects of Huaier extract. The data show that Huaier extract inhibits the expression of H19 and miR-675-5p. The over-expression of $\mathrm{H} 19$ and miR-675-5p reversed the inhibitory effects of Huaier extract, whereas reduced levels of H19 and miR-675-5p sensitized breast cancer cells to Huaier extract. Therefore, this study shows that Huaier extract inhibits breast cancer progression via the H19/miR-675-5p axis. Thus, Huaier extract is a promising therapeutic agent for the clinical treatment of breast cancer.

\section{Materials and Methods}

\section{Cell lines and reagents}

The breast cancer cell lines MDA-MB-231, MDA-MB-468 and MCF7 were purchased from the American Type Culture Collection (Manassas, VA, USA) and were maintained in DMEM/high glucose medium (GibcoBRL, Rockville, IN, USA) supplemented with $10 \%$ fetal bovine serum (CLARK), $100 \mathrm{U} / \mathrm{ml}$ penicillin and 100 $\mu \mathrm{g} / \mathrm{ml}$ streptomycin in $5 \% \mathrm{CO}_{2}$ at $37^{\circ} \mathrm{C}$. Huaier extract was kindly provided by Gaitianli Medicine Co., Ltd. (Jiangsu, China) and was prepared as previously described [14]. MicroRNA mimics, microRNA inhibitors, and siRNA were obtained from GenePharma (Shanghai, China).

\section{Microarray analysis}

Total RNA was extracted from MDA-MB-231 and MCF7 cells and Huaier-treated cells (MDA-MB-231_H and MCF7_H), followed by analysis using GeneChip ${ }^{\circledR}$ Human Transcriptome Array 2.0 (GMINIX, Shanghai, China), according to the manufacturer's instructions. The microarray covered 40, 000 human noncoding transcripts, 245, 000 coding transcripts, and 339, 000 probe sets that covered exon-exon junctions. Each RNA was detected by corresponding probes and analysis was repeated three times.

\section{MTT (3-(4, 5-dimethyl-2-thiazolyl)- 2, 5--diphenyl-2H-tetrazolium bromide) assay}

Cell viability was measured in an MTT assay. Breast cancer cells were initially transfected with the indicated vectors, microRNAs, or siRNAs. At $48 \mathrm{~h}$ post transfection, cells $\left(2 \times 10^{3}\right.$ cells/well) were cultured overnight in 96-well plates. The medium was subsequently replaced with medium that contained various concentrations of Huaier extract $(0,2,4$, or $8 \mathrm{mg} / \mathrm{mL})$. After incubation for the indicated time, $20 \mu \mathrm{L}$ of MTT ( $5 \mathrm{mg} / \mathrm{mL}$ in PBS) was added to each well and the cells were incubated for $4-6 \mathrm{~h}$ at $37^{\circ} \mathrm{C}$. The supernatants were carefully discarded, and $100 \mu \mathrm{L}$ dimethyl sulfoxide (DMSO) was added to each well. Absorbance values were read in a Microplate Reader (Bio-Rad, Hercules, CA, USA) at $490 \mathrm{~nm}$ and $570 \mathrm{~nm}$.

Flow cytometry analysis of apoptosis

The BD Pharmingen ${ }^{\mathrm{TM}}$ PE Annexin V Apoptosis Detection Kit (BD Biosciences, Franklin Lakes, NJ, USA) was used to detect apoptotic cells. Briefly, after transfection with the indicated vectors, microRNAs, and 


\section{Cellular Physiology Cell Physiol Biochem 2017;44:581-593

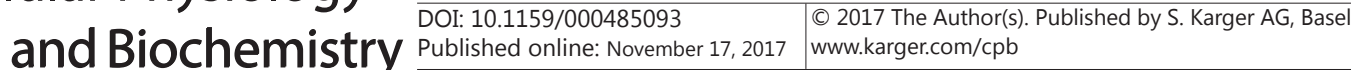

Wang et al.: Huaier Inhibits Breast Cancer Progression

siRNAs, breast cancer cells were treated with various concentrations of Huaier extract for the indicated times. Cells were subsequently harvested and washed twice with PBS. Next, cells $\left(1 \times 10^{5}\right)$ were resuspended in $100 \mu \mathrm{l}$ binding buffer, followed by the addition of $5 \mu \mathrm{l}$ PE Annexin V and $5 \mu \mathrm{l}$ 7-AAD. After incubation for 15 min in the dark, an additional $400 \mu \mathrm{l}$ of binding buffer was added prior to analysis by flow cytometry using a FACScan flow cytometer (BD Biosciences).

Quantitative real-time PCR ( $q$ PCR) analysis

Total RNA was extracted from cells using TRIzol reagent (Invitrogen, Carlsbad, CA, USA) and cDNAs or miRNAs were synthesized using the PrimeScript reverse transcriptase reagent kit (TaKaRa, Shiga, Japan) or the Mir-X ${ }^{\mathrm{TM}}$ miRNA first-strand Synthesis Kit (TaKaRa, Shiga, Japan) respectively. Real-time PCR was performed using an Applied Biosystems StepOne Plus Real-Time PCR System. The PCR products were amplified with the following primers: miR-675-5p forward, 5'- GCGGAGAGGGCCCACAG-3'; H19 forward, 5'- AGCCACCACATCATCCCAGA-3' and H19 reverse, 5'- GAATGCTTGAAGGCTGCTCC-3'; GAPDH forward, 5'GGAGCGAGATCCCTCCAAAAT-3' and GAPDH reverse, 5'- GGCTGTTGTCATACTTCTCATGG-3'. GAPDH or U6 was used to determine equal RNA loading. All experiments were repeated at least three times.

\section{Plasmid construction and transfection}

To overexpress H19, H19 cDNA was cloned into the multiple cloning site of the pcDNA3.1 vector (Invitrogen, Carlsbad, CA, USA). The expression plasmid vector and the empty vector were subsequently transfected into breast cancer cells using lipofectamine 2000 (Thermo Fisher Scientific Inc., Waltham, MA, USA).

Transfection of miRNA and siRNA

MiR-675-5p mimic, miR mimic control, miR-675-5p inhibitor (miR-675-5pI), miR inhibitor control (miR-NCI), specific H19 siRNAs and a scrambled locus siRNA (NC) were purchased from GenePharma (Shanghai, China). Cells were seeded in $60 \mathrm{~mm}$ dishes $\left(4 \times 10^{5} \mathrm{cells} / \mathrm{dish}\right)$ and transfected according to the manufacturer's protocol (Invitrogen, CA, USA). The siRNA sequences for H19 were as follows: H19 siRNA 1, 5'- UAAGUCAUUUGCACUGGUU-3'; H19 siRNA 2, 5'- CCCACAACAUGAAAGAAAC-3'.

Western blot analysis

Indicated cells were lysed with lysis buffer $(1 \times \mathrm{PBS}, 1 \% \mathrm{NP} 40,0.1 \%$ sodium dodecyl sulfate, $5 \mathrm{mM}$ EDTA, $0.5 \%$ sodium deoxycholate and $1 \mathrm{mM}$ sodium orthovanadate) that contained protease inhibitors. Proteins were separated via SDS-PAGE gels and analyzed by Western blotting. An anti-CBL antibody was purchased from Abcam (Cambridge, MA, USA) and a mouse monoclonal antibody against $\beta$-actin was purchased from Sigma-Aldrich (St. Louis, MO, USA). The expression of $\beta$-actin was used as a loading control.

\section{Statistical analysis}

All experiments were performed in triplicate and data are presented as the mean \pm S.D.. SPSS V18.0 software was used for statistical analysis. The data were analyzed with one-way analysis of variance (ANOVA). A $p$-value $<0.05$ was considered statistically significant.

\section{Results}

Huaier extract inhibits expression of 1919 in breast cancer cells

We have previously demonstrated that Huaier extract has anti-tumor effects against breast cancer cells $[4,11,12,31]$. However, the underlying mechanisms were not clear. To identify candidate ncRNAs involved in Huaier-mediated tumor suppression, we examined the ncRNA expression profiles in MDA-MB-231 and MCF7 cells. As shown in Fig. 1A, 1981 human ncRNAs showed a significant change in expression after treatment with Huaier extract. Among these human ncRNAs, 228 were upregulated (including LOC643401, MIR548X, CG030, RPS15AP10, and LINC00240) and 925 were downregulated (including SNORA38, MIR4536-1, RNU1-23P, ATG10-AS1, and LINC00529). Combining data from the ncRNA microarray analysis and literature searches identified lncRNA H19, the expression 
Fig. 1. Huaier extract downregulates expression of H19 in breast cancer cell lines. (A) Heat map showing dysregulated expression of cancer-related noncoding RNAs in MDA-MB-231 and MCF7 cells treated (or not) with Huaier extract. Red represents high expression and green represents low expression. (B) H19 expression levels measured by qPCR. Data are expressed as the mean \pm S.D. of at least three independent experiments. $* * \mathrm{p}<0.01$.

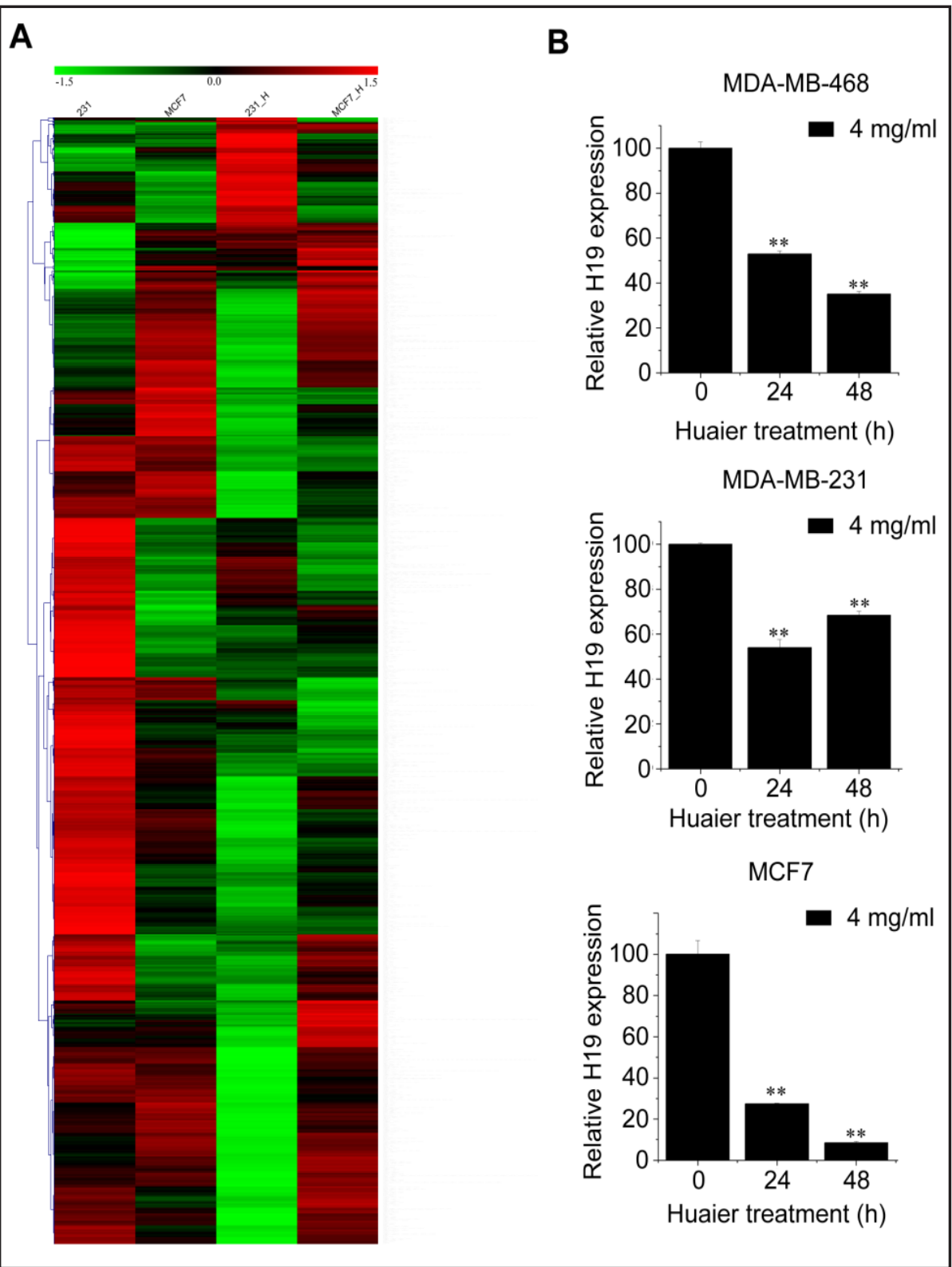

of which decreased in both cell lines after exposure to Huaier extract. qPCR confirmed that Huaier extract reduced H19 expression in a time-dependent manner (Fig. 1B). Taken together, these results show that Huaier extract reduces the H19 levels in breast cancer cells.

\section{Reduced H19 expression promotes Huaier-mediated tumor suppression}

To assess the potential functional role of $\mathrm{H} 19$ on Huaier-mediated tumor suppression, we knocked down the expression of $\mathrm{H} 19$ using siRNA1 and siRNA2 (Fig. 2A). Previous studies have demonstrated that H19 siRNA inhibited the cell viability of cancer cells [32,33], and we obtained the consistent results (Fig. 2B). In our study, the transfection of H19 siRNAs led to a significant increase in the tumor-inhibitory effects of Huaier extract (2 mg/ml) (Fig. 2C). In MDA-MB-231 cells, H19 siRNA1 reduced the cell viability $(51.3 \pm 1.3 \%)$ compared with the control group $(67.0 \pm 5.2 \%)$ after $48 \mathrm{~h}$ of exposure to Huaier extract. H19 siRNA2 had the same effect.

Furthermore, we used flow cytometry analysis to detect apoptotic cells after exposure to Huaier extract and H19 siRNAs. As shown in Fig. 2D, the transfection of H19 siRNA1 led to 
Fig. 2. Knockdown of H19 promotes the tumor suppressive effects of Huaier extract. (A) H19 expression relative to that in control cells decreases in response to specific H19 siRNAs. (B) Effect of H19 inhibition on breast cancer cell proliferation. (C) Combined effect of Huaier extract and H19 siRNAs on cell viability, as measured by an MTT assay. (D) Percentage of apoptotic cells detected by flow cytometry analysis. All experiments were performed in triplicate and data are expressed as the mean \pm S.D. of at least three independent experiments. $\quad * \mathrm{p}<0.05$, ${ }^{* *} \mathrm{p}<0.01$.

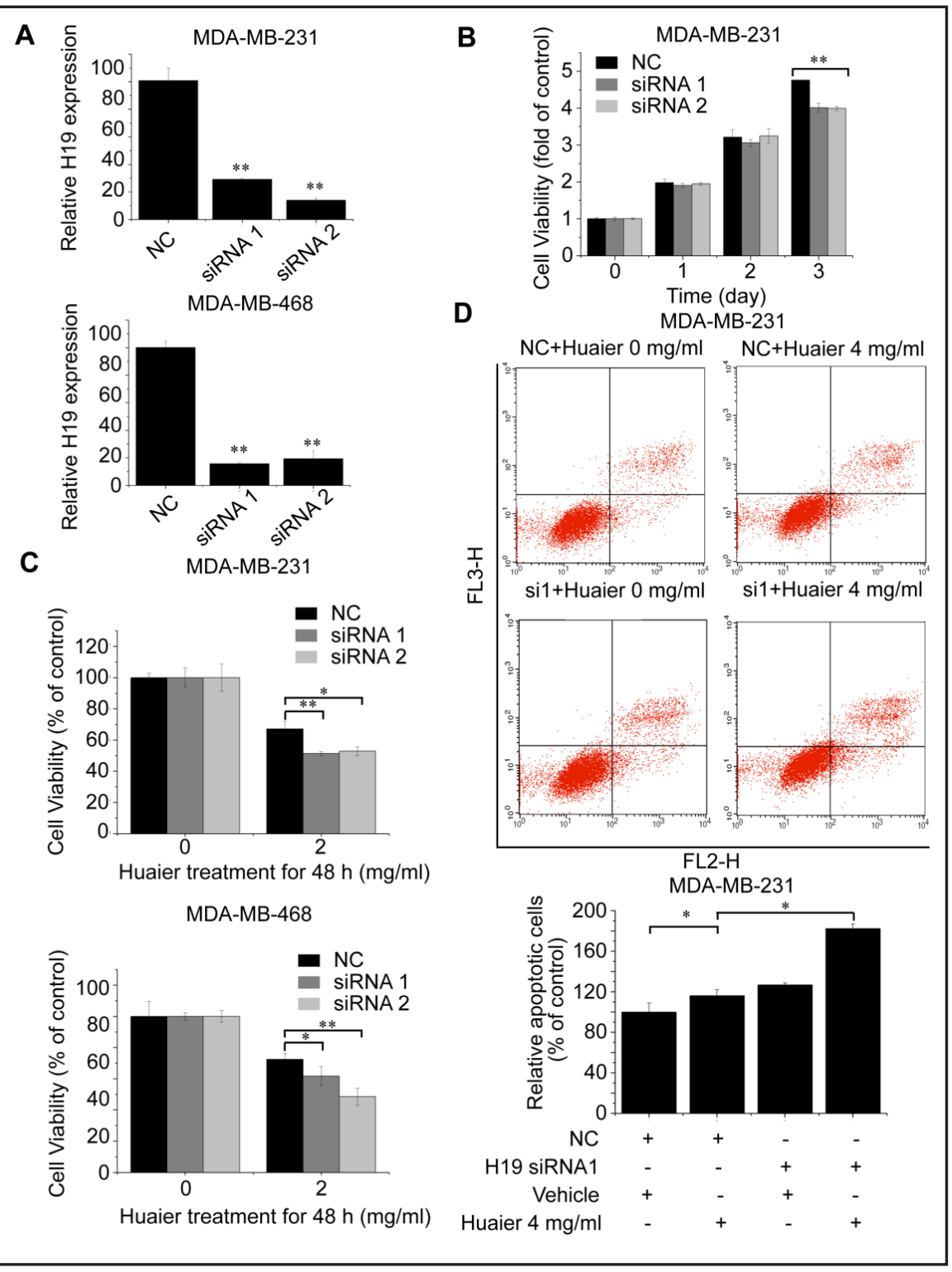

a significant increase (1.57-fold) in the percentage of apoptotic MDA-MB-231 cells compared with the control group ( $p=0.035$ ). These results suggest that knocking down H19 expression increased the anti-tumor effects of Huaier extract.

Increased expression of H19 suppresses the inhibitory effects of Huaier extract

In the present study, the expression of $\mathrm{H} 19$ increased after the transfection of cells with pcDNA3.1-H19. qPCR was used to examine the transfection efficiency (Fig. 3A; $p<0.01$ ). A previous study showed that the overexpression of $\mathrm{H} 19$ promoted the proliferation of breast cancer cells [34], and we demonstrated the same effect (Fig. 3B). The role of H19 was further examined by assessing cell proliferation and apoptosis. In MDA-MB-231 cells, after treatment with $4 \mathrm{mg} / \mathrm{ml}$ Huaier extract for $24 \mathrm{~h}$, the overexpression of $\mathrm{H} 19$ led to significant inhibition of Huaier-induced tumor suppression (Fig. 3C; $p=0.028$ ). The same results were obtained in MDA-MB-468 cells. In addition, the data shown in Fig. 3D demonstrate that the increased expression of $\mathrm{H} 19$ reduced the percentage of apoptotic cells by 0.65 -fold $(p=0.025)$. Taken together, these findings indicate that H19 plays a major role in Huaier-mediated tumor suppression. 
Fig. 3. Overexpression of H19 reverses the inhibitory effects of Huaier extract. (A) Transfection of pcDNA3.1-H19 increased the expression level of $\mathrm{H} 19$ in breast cancer cells. qPCR was performed to examine the transfection efficiency. (B) Effect of H19 overexpression on breast cancer cell proliferation. (C) The combined effects of Huaier extract and an H19 overexpression vector (H19) on cell viability were measured by an MTT assay. (D) The percentage of apoptotic cells was measured via flow cytometry analysis. All experiments were performed in triplicate and data are expressed as the mean \pm S.D. of at least three independent experiments. ${ }^{*} \mathrm{p}<0.05$, ${ }^{* *} \mathrm{p}<0.01$.

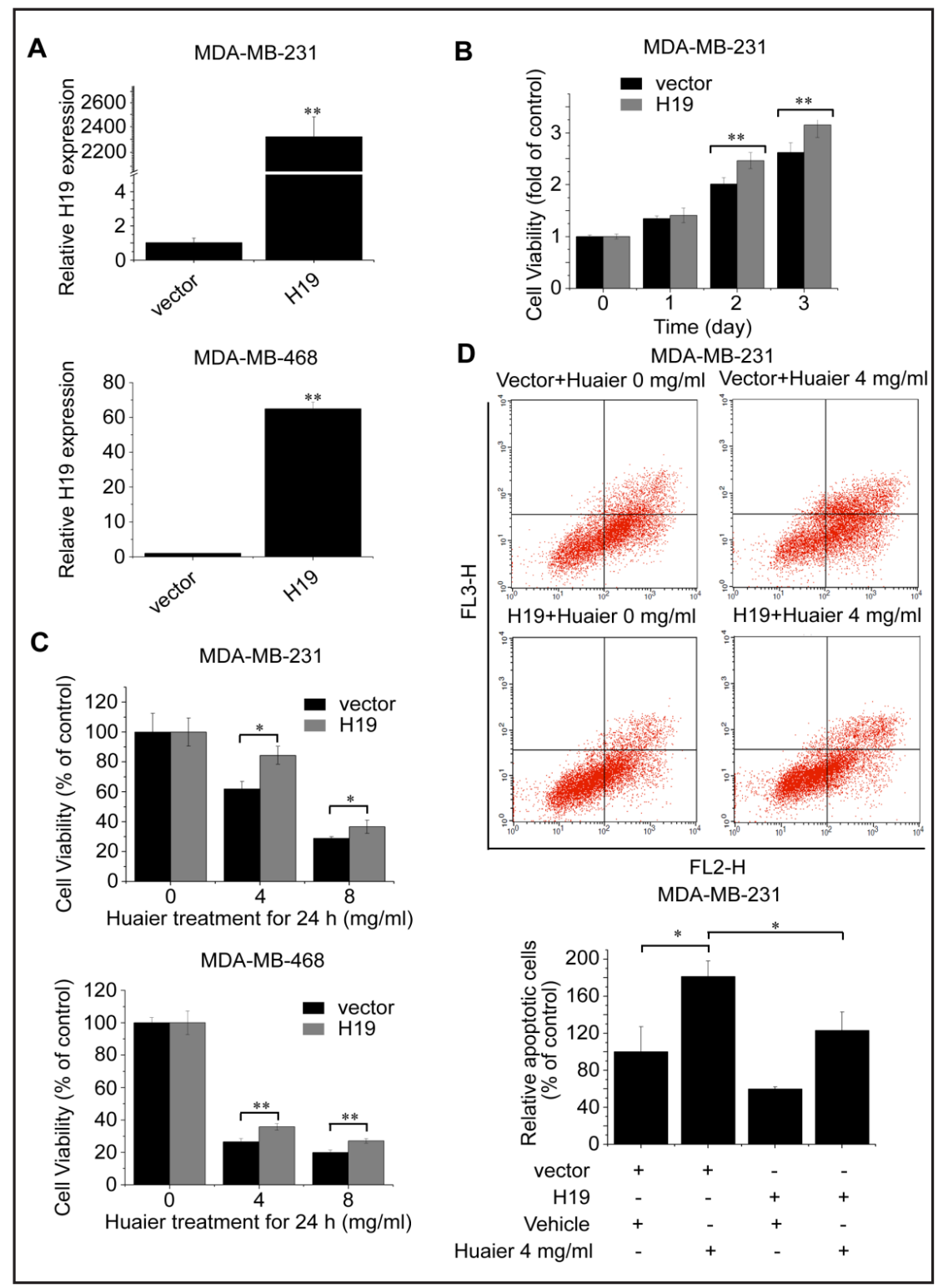

miR-675-5p reduces the sensitivity of breast cancer cells to Huaier extract

Previous studies demonstrate that H19 exon 1 encodes the precursor for miR-675, which generates two conserved miRNAs (miR-675-5p and miR-675-3p) [27, 29, 35, 36]. Therefore, we explored the possibility that miR-675-5p was associated with the function of H19 in Huaier-mediated tumor suppression.

As shown in Fig. 4A, treatment with Huaier extract led to a significant and dose-dependent reduction in the miR-675-5p expression by MDA-MB-468 and MDA-MB-231 cells. The miR675-5p level was significantly upregulated after transfection with miR-675-5p mimics (Fig. 4B). Fig. 4C shows that the over-expression of miR-675-5p led to a slight suppression of Huaier extract-mediated suppression of breast cancer proliferation. Therefore, miR-675-5p is involved in the anti-tumor function of Huaier extract.

\section{Inhibition of miR-675-5p sensitizes breast cancer cells to Huaier extract}

The expression of miR-675-5p in MDA-MB-231 cells was reduced by a miR-675-5p inhibitor (Fig. 5A). Downregulation of miR-675-5p increased the anti-tumor effects of Huaier extract. In MDA-MB-231 cells, treatment with Huaier extract for $48 \mathrm{~h}$ led to a significant 
Fig. 4. miR-675$5 \mathrm{p}$ rescues the cytotoxic effects of Huaier extract. (A) Huaier extract reduced expression of miR675-5p in MDAMB-468 and M D A - M B - 231 cells in a dosedependent manner. (B) qPCR was performed to measure the transfection efficiency of miR675-5p mimics. (C) The combined effect of Huaier extract and miR675-5p on cell viability was measured by an MTT assay. All experiments were performed in triplicate and data are expressed as the mean \pm S.D. of at least three independent experiments. ${ }^{*} \mathrm{p}<0.05$, $* * \mathrm{p}<0.01$.
A
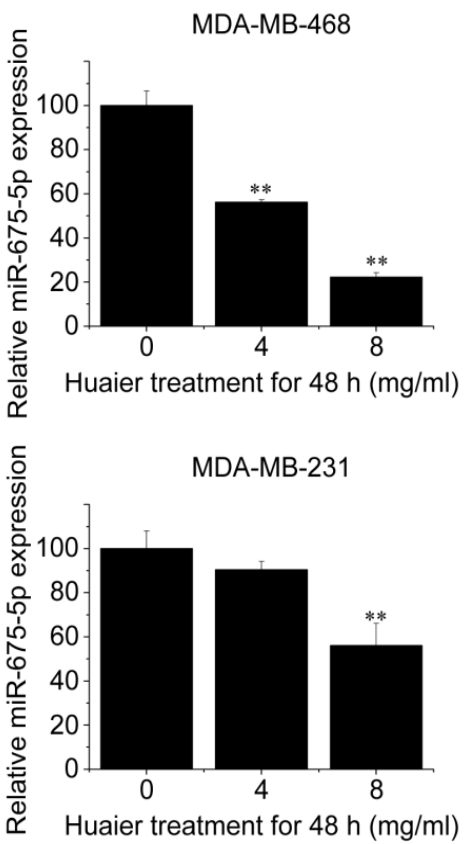

B

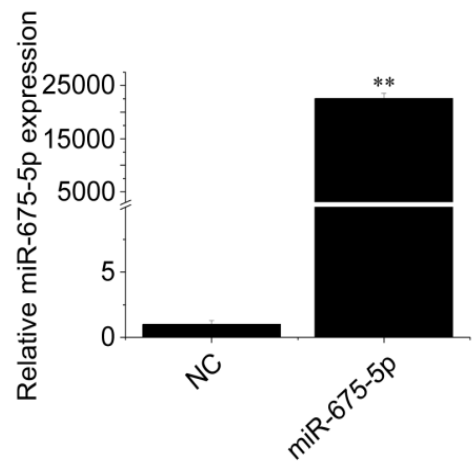

C
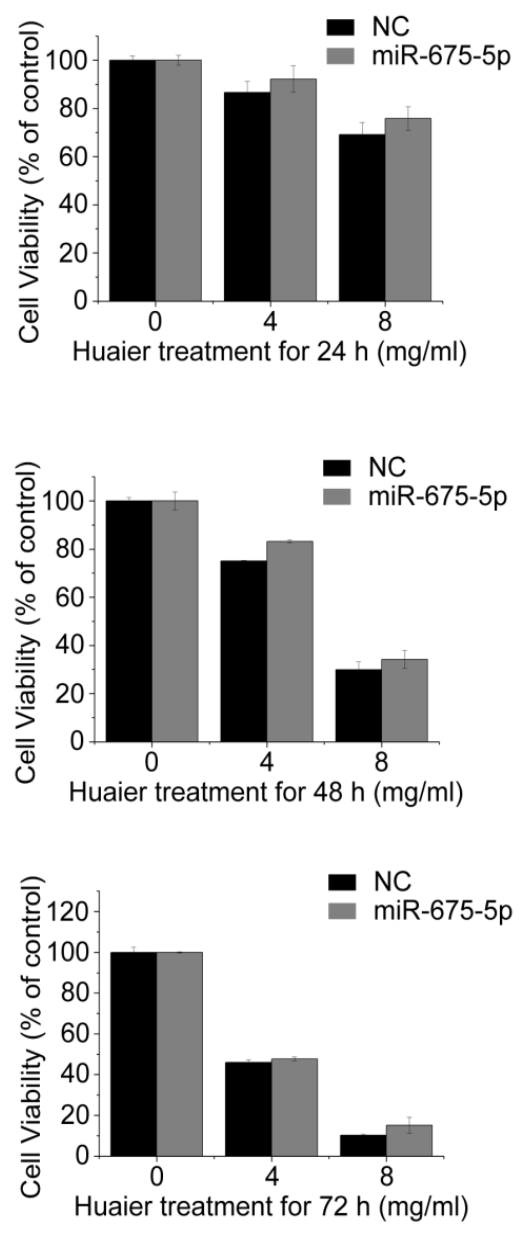

reduction in the viability of breast cancer cells (from $74.9 \pm 6.8 \%$ in the NCI group to $59.1 \pm 8.0 \%$ in the miR- $675-5 \mathrm{pI}$ group; $p=0.030$; Fig. $5 \mathrm{~B}$ ). Similar results were obtained when MDA-MB-468 cells were treated with Huaier extract. Flow cytometry analysis was further applied to detect the effect of miR-675-5p on apoptosis. As shown in Fig. 5C, inhibition of miR-675-5p significantly increased the percentage of apoptotic cells induced by Huaier extract $(p=0.019)$. These results showed that the downregulation of miR-675-5p promoted the cytotoxicity effect of Huaier extract.

\section{CBL plays a role in the inhibitory effect of Huaier extract}

Vennin et al. previously demonstrated that CBL was a direct target of miR-675-5p [29]. H19/miR-675-5p increases cell proliferation by regulating CBL. In addition, we previously showed that Huaier increased the CBL expression via microarray profiling on protein-coding genes [37]. Therefore, we supposed that CBL may be linked to the H19/miR-675-5p axis and may play a role in mediating the cytotoxic effects of Huaier extract. Fig. $6 \mathrm{~A}$ shows that the CBL expression in breast cancer cells increased in a dose-dependent manner after exposure to Huaier extract, which was consistent with our previous microarray data [37]. As shown in Fig. 6B, the overexpression miR-675-5p decreased the expression of CBL. However, the inhibition of miR-675-5p exerted the opposite effect. Treatment with Huaier extract rescued

\section{KARGER}


Fig. 5. Inhibition of endogenous miR-675-5p increases the therapeutic potential of Huaier extract. (A) An miR-675$5 \mathrm{p}$ inhibitor (miR675-5pI) reduced the levels of miR675-5p. (B) The combined effect of Huaier extract and miR-675-5pI on cell viability was measured by an MTT assay. (C) The percentage of apoptotic cells was measured by flow cytometry. All experiments were performed in triplicate and data are expressed as the mean \pm S.D. of at least three independent experiments. ${ }^{*} \mathrm{p}<0.05$, ${ }^{* *} \mathrm{p}<0.01$.

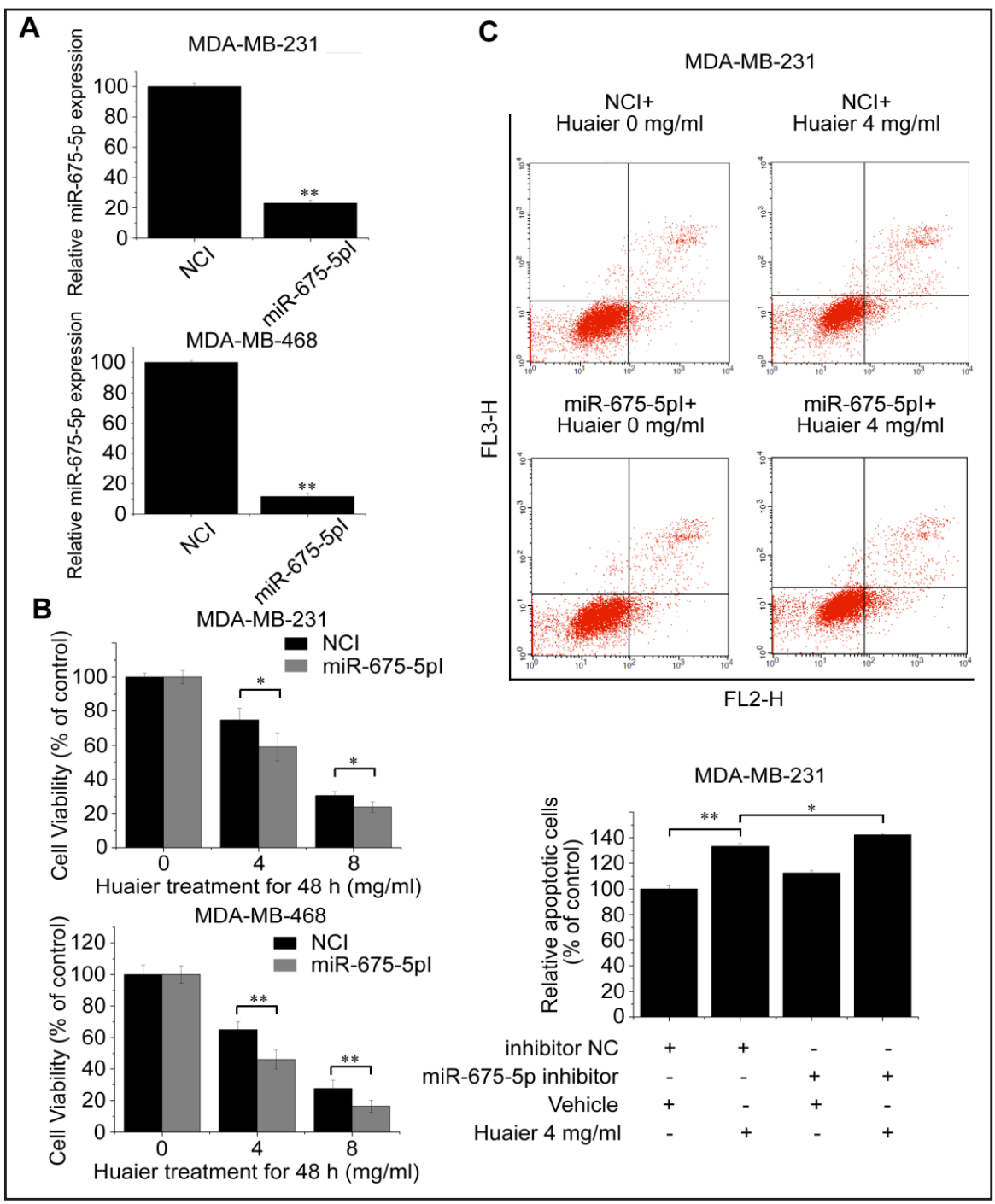

the suppression effect of miR-675-5p on the CBL expression, which was consistent with the previous study [29]. Thus, CBL plays a critical role in Huaier extract-mediated tumor suppression. In summary, Huaier extract reduced the expression of H19 and miR-675-5p, thereby inhibiting breast cancer progression through increasing CBL (Fig. 7).

\section{Discussion}

TCM has gained increasing attention because of its role in cancer prevention and treatment [38-40]. Huaier extract has been used in China for approximately 1600 years [4]; however, its anti-tumor effects were confirmed more recently $[8,13,41]$. We have previously demonstrated that Huaier extract induces autophagy and apoptosis [4, 11,31], regulates tumor-associated macrophages [10], inhibits cancer stem cells [12], and suppresses the $\mathrm{ER} \alpha$ signaling pathway [13]. However, its underlying mechanisms were not completely understood. Here, we examined the role of lncRNAs in Huaier-mediated tumor suppression. The data demonstrate that Huaier extract inhibits breast cancer progression by regulating the H19/miR-675-5p axis. To the best of our knowledge, this investigation represents the first report to demonstrate the participation of IncRNA in Huaier-mediated cytotoxicity. 
Fig. 6. Huaier extract increases expression of CBL via miR-675-5p.

Cells were treated with various concentrations of Huaier extract for the indicated times. (B) Cells were exposed to miR-675-5p or miR-675-5pI combined with or without Huaier extract. Cell lysates were prepared and examined by Western blot analysis. The results are representative of three independent experiments. All experiments were performed in triplicate, and data are expressed as the mean \pm S.D. of at least three independent experiments. ${ }^{* *} \mathrm{p}<0.01$.

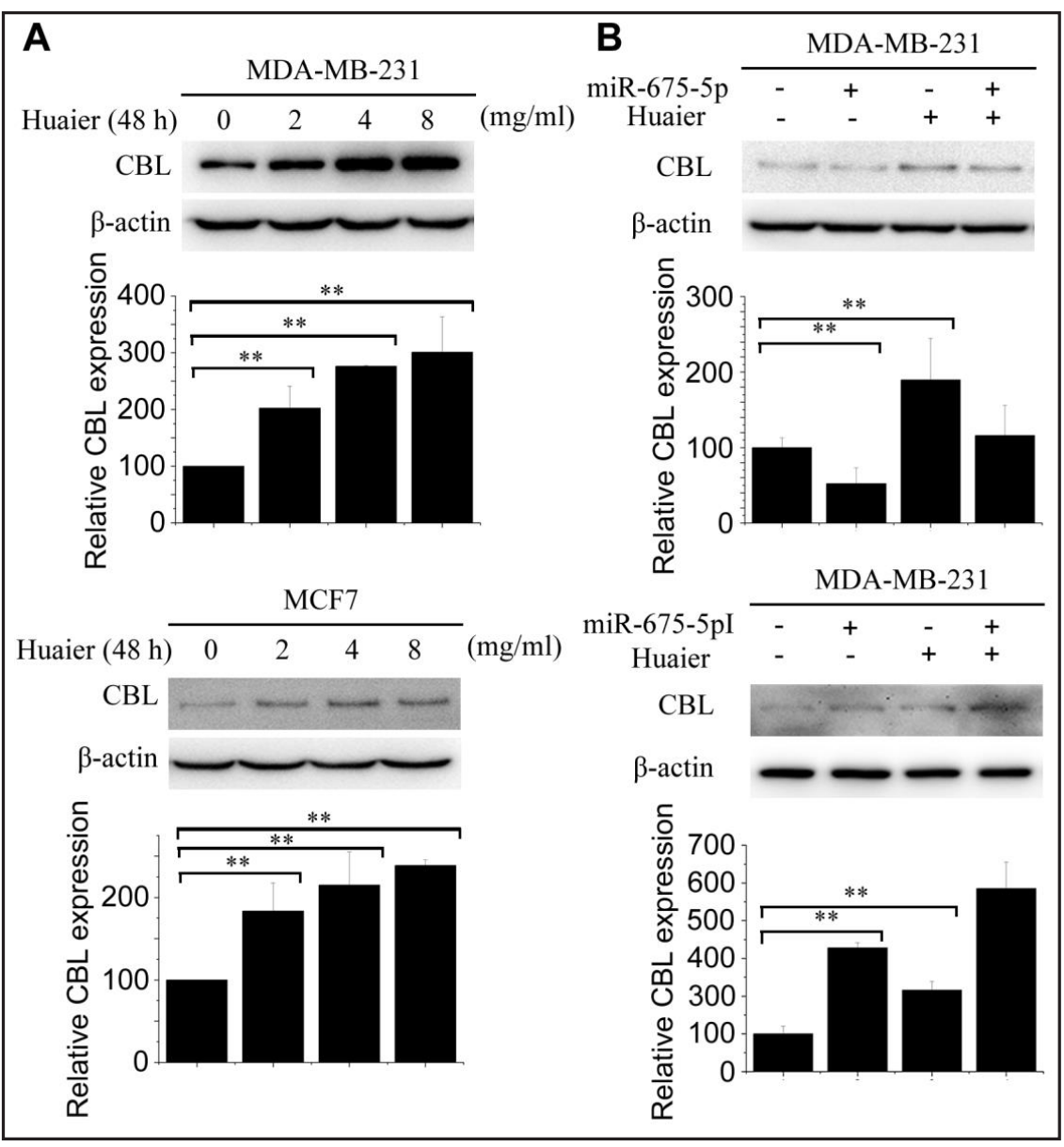

Fig. 7. Huaier extract inhibits breast cancer progression through a IncRNA-H19/miR675-5p pathway. Huaier extract reduced the expression of H19 and miR-675-5p, thereby inhibiting breast cancer progression. The Fig. was drawn by X.W.

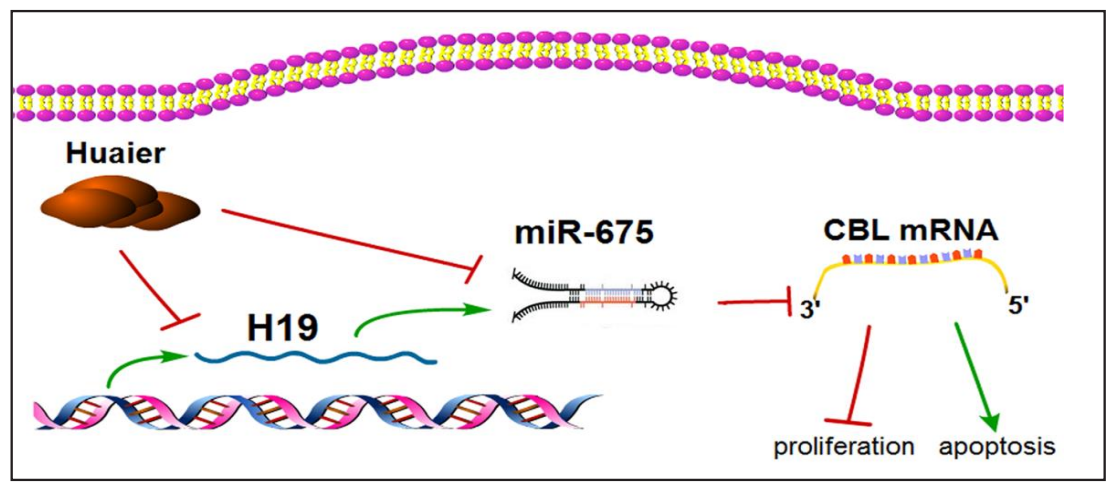

LncRNAs are a class of RNAs longer than 200 nucleotides that lack protein-coding potential [42]. An increasing number of lncRNAs have been identified as playing critical roles in cancer development and progression [43-45]. LncRNA H19 is located on the 11p15.5 locus and functions as an oncogene in several cancers [46-48]. Here, we initially analyzed IncRNA microarray profiles to identify candidate lncRNAs associated with the cytotoxic role of Huaier extract. H19 was among the most downregulated lncRNAs. qPCR data confirmed that Huaier extract inhibited the expression of H19 in three breast cancer cell lines. As shown in Fig. 1B, exposure to Huaier extract for $24 \mathrm{~h}$ significantly reduced the expression of H19. The detail mechanisms that underlie the suppression will be discovered in our future

\section{KARGER}




\section{Cellular Physiology \begin{tabular}{l|l|l} 
and Biochemistry & $\begin{array}{l}\text { DOI: 10.1159/000485093 } \\
\text { Published onlIne: November 17, } 2017\end{array}$ & $\begin{array}{l}\text { C) } 2017 \text { The Author(s). Published by S. Karger AG, Basel } \\
\text { www.karger.com/cpb }\end{array}$ \\
\hline
\end{tabular} \\ Wang et al.: Huaier Inhibits Breast Cancer Progression}

research. The knockdown of H19 sensitized breast cancer cells to Huaier extract; however, the overexpression of H19 reversed the effect of Huaier extracts. Taken together, these data show that the cytotoxic effects of Huaier extract against breast cancer cells are mediated by H19.

Of all ncRNAs, microRNAs have been the subject of substantial studies, many of which have verified their roles in breast cancer development and progression [49-52]. Increasing evidence suggests cross-regulation between microRNAs and lncRNAs [53]. LncRNAs may function as a molecular sponge or a precursor that regulates both the expression and function of miRNAs [54,55]. miR-675-5p is derived from the first exon of $\mathrm{H} 19$, and its expression in gastric cancer positively correlates with $\mathrm{H} 19$ expression [56]. Recent studies have indicated that miR-675-5p regulates several H19-mediated effects, including intestinal epithelial barrier function, osteoblast differentiation and cancer invasion [23, 30, 35]. We previously performed a miRNA microarray profiling that compared breast cancer tissues with normal breast tissues [57]. According to the data, 21 miRNAs were upregulated, and 27 miRNAs were downregulated. MiR-675-5p was among the most upregulated miRNAs, which predicted the oncogenic effects of miR-675-5p. As shown in Fig. 4C, the overexpression of miR-675-5p reduced the inhibitory effect of Huaier extract on cell proliferation; however, the inhibition of miR-675-5p increased the effect of Huaier extract on the cell viability and apoptosis (Fig. $5 \mathrm{~B}$ and $\mathrm{C}$ ). These data demonstrated that miR-675-5p promoted the progression of breast cancer cells after exposure to Huaier extract. In addition, we determined that Huaier extract suppressed the expression of miR-675-5p in breast cancer cells. As shown in Fig. 4A, Huaier extract inhibited the levels of miR-675-5p in a dose-dependent manner, which indicated that Huaier extract exerted its anti-tumor effect via miR-675-5p inhibition. CBL is a direct target of miR-675-5p [29]. The current data show that Huaier extract increases the expression of CBL. Therefore, miR-675-5p mediates the function of H19 by targeting CBL. However, in a recent study, Costa et al. demonstrated that miR-675-5p exerted a metastatic phenotype through an $\mathrm{H} 19$ independent mechanism [58]. Thus, further research should be performed to investigate whether Huaier extract could directly affect miR-675-5p.

\section{Conclusion}

In summary, the expression levels of H19, miR-675-5p and CBL in breast cancer cell lines are affected by Huaier extract. The overexpression of H19 or miR-675-5p reverses the tumor-inhibitory effects of Huaier extract. However, knocking down H19 or miR-675-5p sensitizes breast cancer cells to Huaier extract. These data provide evidence that Huaier extract inhibits breast cancer cell proliferation and induces apoptosis via the lncRNA H19/ miR-675-5p/CBL signaling pathway. Thus, we have identified a novel mechanism that underlies the anti-tumor effects of Huaier extract, a TCM that has potential as a clinical treatment for breast cancer.

\section{Acknowledgements}

This work was supported by the National Natural Science Foundation of China (No. 81272903; No. 81672613), Key Research and Development Program of Shandong Province (No. 2016GGE2775), and Special Support Plan for National High Level Talents ("Ten Thousand Talents Program") to Qifeng Yang.

J.W., L.J. and Q.Y. designed and performed the study. J.W. and X.W. wrote the manuscript. T.C. analyzed the data. X.W.drew the figures. J.W., L.J. and X.W. conducted most of the experiments. All authors reviewed the manuscript.

\section{Disclosure Statement}

The authors have no conflict of interest. 


\section{Cellular Physiology Cell Physiol Biochem 2017;44:581-593

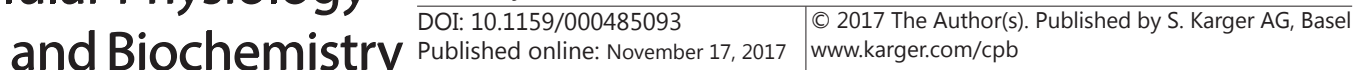 \\ \begin{tabular}{l|l|l} 
Published onlIne: November 17, 2017 & www.karger.com/cp \\
\hline
\end{tabular}}

\section{References}

1 Torre LA, Bray F, Siegel RL, Ferlay J, Lortet-Tieulent J, Jemal A: Global cancer statistics, 2012. CA Cancer J Clin 2015;65:87-108.

2 Cohen I, Tagliaferri M, Tripathy D: Traditional Chinese medicine in the treatment of breast cancer. Semin Oncol 2002;29:563-574.

-3 Xu W, Towers AD, Li P, Collet JP: Traditional Chinese medicine in cancer care: perspectives and experiences of patients and professionals in China. Eur J Cancer Care (Engl) 2006;15:397-403.

-4 Zhang N, Kong X, Yan S, Yuan C, Yang Q: Huaier aqueous extract inhibits proliferation of breast cancer cells by inducing apoptosis. Cancer Sci 2010;101:2375-2383.

-5 Zhang F, Zhang Z, Liu Z: Effects of Huaier aqueous extract on proliferation and apoptosis in the melanoma cell line A875 Acta Histochem 2013;115:705-711.

-6 Zheng J, Li C, Wu X, Liu M, Sun X, Yang Y, Hao M, Sheng S, Sun Y, Zhang H, Long J, Liang Y, Hu C: Astrocyte elevated gene-1 (AEG-1) shRNA sensitizes Huaier polysaccharide (HP)-induced anti-metastatic potency via inactivating downstream P13K/Akt pathway as well as augmenting cell-mediated immune response. Tumour Biol 2014;35:4219-4224.

7 Li C, Wu X, Zhang H, Yang G, Hao M, Sheng S, Sun Y, Long J, Hu C, Sun X, Li L, Zheng J: A Huaier polysaccharide restrains hepatocellular carcinoma growth and metastasis by suppression angiogenesis. Int J Biol Macromol 2015;75:115-120.

8 Zheng J, Li C, Wu X, Liu M, Sun X, Yang Y, Hao M, Sheng S, Sun Y, Zhang H, Long J, Liang Y, Hu C: Huaier polysaccharides suppresses hepatocarcinoma MHCC97-H cell metastasis via inactivation of EMT and AEG1 pathway. Int J Biol Macromol 2014;64:106-110.

-9 Hu Z, Yang A, Fan H, Wang Y, Zhao Y, Zha X, Zhang H, Tu P: Huaier aqueous extract sensitizes cells to rapamycin and cisplatin through activating mTOR signaling. J Ethnopharmacol 2016;186:143-150.

10 Li Y, Qi W, Song X, Lv S, Zhang H, Yang Q: Huaier extract suppresses breast cancer via regulating tumorassociated macrophages. Sci Rep 2016;6:20049.

-11 Wang X, Qi W, Li Y, Zhang N, Dong L, Sun M, Cun J, Zhang Y, Lv S, Yang Q: Huaier Extract Induces Autophagic Cell Death by Inhibiting the mTOR/S6K Pathway in Breast Cancer Cells. PLoS One 2015;10:e0131771.

12 Wang X, Zhang N, Huo Q Sun M, Dong L, Zhang Y, Xu G, Yang Q: Huaier aqueous extract inhibits stemlike characteristics of MCF7 breast cancer cells via inactivation of hedgehog pathway. Tumour Biol 2014;35:10805-10813.

13 Wang X, Zhang N, Huo Q Sun M, Lv S, Yang Q: Huaier aqueous extract suppresses human breast cancer cell proliferation through inhibition of estrogen receptor alpha signaling. Int J Oncol 2013;43:321-328.

14 Wang X, Zhang N, Huo Q Yang Q: Anti-angiogenic and antitumor activities of Huaier aqueous extract. Oncol Rep 2012;28:1167-1175.

15 Marshall L, White RJ: Non-coding RNA production by RNA polymerase III is implicated in cancer. Nat Rev Cancer 2008;8:911-914.

16 Patel JS, Hu M, Sinha G, Walker ND, Sherman LS, Gallagher A, Rameshwar P: Non-coding RNA as mediators in microenvironment-breast cancer cell communication. Cancer Lett 2016;380:289-295.

-17 Dey BK, Mueller AC, Dutta A: Long non-coding RNAs as emerging regulators of differentiation, development, and disease. Transcription 2014;5:e944014.

-18 Huang NS, Chi YY, Xue JY, Liu MY, Huang S, Mo M, Zhou SL, Wu J: Long non-coding RNA metastasis associated in lung adenocarcinoma transcript 1 (MALAT1) interacts with estrogen receptor and predicted poor survival in breast cancer. Oncotarget 2016;7:37957-37965.

19 Wang J, Ye C, Xiong H, Shen Y, Lu Y, Zhou J, Wang L: Dysregulation of long non-coding RNA in breast cancer: an overview of mechanism and clinical implication. Oncotarget 2017;8:5508-5522.

20 Wu C, Luo J: Long Non-Coding RNA (lncRNA) Urothelial Carcinoma-Associated 1 (UCA1) Enhances Tamoxifen Resistance in Breast Cancer Cells via Inhibiting mTOR Signaling Pathway. Med Sci Monit 2016;22:3860-3867.

21 Ariel I, Miao HQ, Ji XR, Schneider T, Roll D, de Groot N, Hochberg A, Ayesh S: Imprinted H19 oncofetal RNA is a candidate tumour marker for hepatocellular carcinoma. Mol Pathol 1998;51:21-25.

22 Luo M, Li Z, Wang W, Zeng Y, Liu Z, Qiu J: Long non-coding RNA H19 increases bladder cancer metastasis by associating with EZH2 and inhibiting E-cadherin expression. Cancer Lett 2013;333:213-221. 


\section{Cellular Physiology Cell Physiol Biochem 2017;44:581-593 \begin{tabular}{l|l|l} 
and Biochemistry Published onlIne: November 17, 2017 & $\begin{array}{l}\text { (c) } 2017 \text { The Author(s). Published by S. Karger AG, Basel } \\
\text { www.karger.com/cpb }\end{array}$ \\
\hline
\end{tabular}}

Wang et al.: Huaier Inhibits Breast Cancer Progression

23 Shi Y, Wang Y, Luan W, Wang P, Tao T, Zhang J, Qian J, Liu N, You Y: Long non-coding RNA H19 promotes glioma cell invasion by deriving miR-675 PLoS One 2014;9:e86295.

24 Ma L, Tian X, Wang F, Zhang Z, Du C, Xie X, Kornmann M, Yang Y: The long noncoding RNA H19 promotes cell proliferation via E2F-1 in pancreatic ductal adenocarcinoma. Cancer Biol Ther 2016;17:1051-1061.

25 Zhou X, Ye F, Yin C, Zhuang Y, Yue G, Zhang G: The Interaction Between MiR-141 and lncRNA-H19 in Regulating Cell Proliferation and Migration in Gastric Cancer. Cell Physiol Biochem 2015;36:1440-1452.

26 Gao WL, Liu M, Yang Y, Yang H, Liao Q Bai Y, Li YX, Li D, Peng C, Wang YL: The imprinted H19 gene regulates human placental trophoblast cell proliferation via encoding miR-675 that targets Nodal Modulator 1 (NOMO1). RNA Biol 2012;9:1002-1010.

-27 Liu C, Chen Z, Fang J, Xu A, Zhang W, Wang Z: H19-derived miR-675 contributes to bladder cancer cell proliferation by regulating p53 activation. Tumour Biol 2016;37:263-270.

28 Liu G, Xiang T, Wu QF, Wang WX: Long Noncoding RNA H19-Derived miR-675 Enhances Proliferation and Invasion via RUNX1 in Gastric Cancer Cells. Oncol Res 2016;23:99-107.

29 Vennin C, Spruyt N, Dahmani F, Julien S, Bertucci F, Finetti P, Chassat T, Bourette RP, Le Bourhis X, Adriaenssens E: H19 non coding RNA-derived miR-675 enhances tumorigenesis and metastasis of breast cancer cells by downregulating c-Cbl and Cbl-b. Oncotarget 2015;6:29209-29223.

30 Zou T, Jaladanki SK, Liu L, Xiao L, Chung HK, Wang JY, Xu Y, Gorospe M, Wang JY: H19 Long Noncoding RNA Regulates Intestinal Epithelial Barrier Function via MicroRNA 675 by Interacting with RNA-Binding Protein HuR. Mol Cell Biol 2016;36:1332-1341.

-31 Qi W, Sun M, Kong X, Li Y, Wang X, Lv S, Ding X, Gao S, Cun J, Cai C, Wang X, Chen J, Yin A, Yang Q: Huaier extract synergizes with tamoxifen to induce autophagy and apoptosis in ER-positive breast cancer cells. Oncotarget 2016;7:26003-26015.

-32 Han D, Gao X, Wang M, Qiao Y, Xu Y, Yang J, Dong N, He J, Sun Q, Lv G, Xu C, Tao J, Ma N: Long noncoding RNA H19 indicates a poor prognosis of colorectal cancer and promotes tumor growth by recruiting and binding to eIF4A3. Oncotarget 2016;7:22159-22173.

33 Wu T, Qu L, He G, Tian L, Li L, Zhou H, Jin Q, Ren J, Wang Y, Wang J, Kan X, Liu M, Shen J, Guo M, Sun Y: Regulation of laryngeal squamous cell cancer progression by the lncRNA H19/miR-148a-3p/DNMT1 axis. Oncotarget 2016;7:11553-11566.

-34 Li Z, Li Y, Li Y, Ren K, Li X, Han X, Wang J: Long non-coding RNA H19 promotes the proliferation and invasion of breast cancer through upregulating DNMT1 expression by sponging miR-152. J Biochem Mol Toxicol 2017;31. DOI: 10.1002/jbt.21933.

35 Huang Y, Zheng Y, Jia L, Li W: Long Noncoding RNA H19 Promotes Osteoblast Differentiation Via TGFbeta1/Smad3/HDAC Signaling Pathway by Deriving miR-675 Stem Cells 2015;33:3481-3492.

-36 Zhu M, Chen Q, Liu X, Sun Q, Zhao X, Deng R, Wang Y, Huang J, Xu M, Yan J, Yu J: IncRNA H19/miR-675 axis represses prostate cancer metastasis by targeting TGFBI. FEBS J 2014;281:3766-3775.

37 Kong X, Ding X, Yang Q: Identification of multi-target effects of Huaier aqueous extract via microarray profiling in triple-negative breast cancer cells. Int J Oncol 2015;46:2047-2056.

-38 Wang J, Yang S, Cai X, Dong J, Chen Z, Wang R, Zhang S, Cao H, Lu D, Jin T, Nie Y, Hao J, Fan D: Berberine inhibits EGFR signaling and enhances the antitumor effects of EGFR inhibitors in gastric cancer. Oncotarget 2016;7:76076-76086.

39 Liu N, Li L, Zhu X, Ling Z, Feng J, Hu Y, Wang Y, Mou L, Wang Y: A High Content Screening Assay to Identify Compounds with Anti-Epithelial-Mesenchymal Transition Effects from the Chinese Herbal Medicine TongMai-Yang-Xin-Wan. Molecules 2016;21. DOI: 10.3390/molecules21101340.

40 Wang H, Chen X, Li T, Xu J, Ma Y: A myrsinol diterpene isolated from a traditional herbal medicine, LANGDU reverses multidrug resistance in breast cancer cells. J Ethnopharmacol 2016;194:1-5.

41 Wu T, Chen W, Liu S, Lu H, Wang H, Kong D, Huang X, Kong Q Ning Y, Lu Z: Huaier suppresses proliferation and induces apoptosis in human pulmonary cancer cells via upregulation of miR-26b-5p. FEBS Lett 2014;588:2107-2114.

42 Batista PJ, Chang HY: Long noncoding RNAs: cellular address codes in development and disease. Cell 2013;152:1298-1307.

43 Kogo R, Shimamura T, Mimori K, Kawahara K, Imoto S, Sudo T, Tanaka F, Shibata K, Suzuki A, Komune S, Miyano S, Mori M: Long noncoding RNA HOTAIR regulates polycomb-dependent chromatin modification and is associated with poor prognosis in colorectal cancers. Cancer Res 2011;71:6320-6326. 


\section{Cellular Physiology Cell Physiol Biochem 2017;44:581-593 \begin{tabular}{ll|l} 
DOI: 10.1159/000485093 & $\begin{array}{l}\text { O 2017 The Author(s). Published by S. Karger AG, Basel } \\
\text { wwww.karger.com/cpb }\end{array}$
\end{tabular}}

Wang et al.: Huaier Inhibits Breast Cancer Progression

44 Schmidt LH, Spieker T, Koschmieder S, Schaffers S, Humberg J, Jungen D, Bulk E, Hascher A, Wittmer D, Marra A, Hillejan L, Wiebe K, Berdel WE, Wiewrodt R, Muller-Tidow C: The long noncoding MALAT-1 RNA indicates a poor prognosis in non-small cell lung cancer and induces migration and tumor growth. J Thorac Oncol 2011;6:1984-1992.

45 Qin R, Chen Z, Ding Y, Hao J, Hu J, Guo F: Long non-coding RNA MEG3 inhibits the proliferation of cervical carcinoma cells through the induction of cell cycle arrest and apoptosis. Neoplasma 2013;60:486-492.

-46 Jiang X, Yan Y, Hu M, Chen X, Wang Y, Dai Y, Wu D, Wang Y, Zhuang Z, Xia H: Increased level of H19 long noncoding RNA promotes invasion, angiogenesis, and stemness of glioblastoma cells. J Neurosurg 2016;124:129-136.

-47 Yan L, Zhou J, Gao Y, Ghazal S, Lu L, Bellone S, Yang Y, Liu N, Zhao X, Santin AD, Taylor H, Huang Y: Regulation of tumor cell migration and invasion by the H19/let-7 axis is antagonized by metformininduced DNA methylation. Oncogene 2015;34:3076-3084.

-48 Wang SH, Ma F, Tang ZH, Wu XC, Cai Q Zhang MD, Weng MZ, Zhou D, Wang JD, Quan ZW: Long non-coding RNA H19 regulates FOXM1 expression by competitively binding endogenous miR-342-3p in gallbladder cancer. J Exp Clin Cancer Res 2016;35:160.

-49 Flores-Perez A, Marchat LA, Rodriguez-Cuevas S, Bautista-Pina V, Hidalgo-Miranda A, Ocampo EA, Martinez MS, Palma-Flores C, Fonseca-Sanchez MA, Astudillo-de la Vega H, Ruiz-Garcia E, Gonzalez-Barrios JA, PerezPlasencia C, Streber ML, Lopez-Camarillo C: Dual targeting of ANGPT1 and TGFBR2 genes by miR-204 controls angiogenesis in breast cancer. Sci Rep 2016;6:34504.

50 Ho JY, Hsu RJ, Liu JM, Chen SC, Liao GS, Gao HW, Yu CP: MicroRNA-382-5p aggravates breast cancer progression by regulating the RERG/Ras/ERK signaling axis. Oncotarget 2017;8:22443-22459.

51 Li J, Song ZJ, Wang YY, Yin Y, Liu Y, Nan X: Low levels of serum miR-99a is a predictor of poor prognosis in breast cancer. Genet Mol Res 2016;15. DOI: 10.4238/gmr.15038338.

52 Taipaleenmaki H, Farina NH, van Wijnen AJ, Stein JL, Hesse E, Stein GS, Lian JB: Antagonizing miR-218$5 p$ attenuates Wnt signaling and reduces metastatic bone disease of triple negative breast cancer cells. Oncotarget 2016;7:79032-79046.

-53 Yoon JH, Abdelmohsen K, Gorospe M: Functional interactions among microRNAs and long noncoding RNAs. Semin Cell Dev Biol 2014;34:9-14.

54 Liu XH, Sun M, Nie FQ, Ge YB, Zhang EB, Yin DD, Kong R, Xia R, Lu KH, Li JH, De W, Wang KM, Wang ZX: Lnc RNA HOTAIR functions as a competing endogenous RNA to regulate HER2 expression by sponging miR331-3p in gastric cancer. Mol Cancer 2014;13:92.

55 Tsang WP, Ng EK, Ng SS, Jin H, Yu J, Sung JJ, Kwok TT: Oncofetal H19-derived miR-675 regulates tumor suppressor RB in human colorectal cancer. Carcinogenesis 2010;31:350-358.

56 Keniry A, Oxley D, Monnier P, Kyba M, Dandolo L, Smits G, Reik W: The H19 lincRNA is a developmental reservoir of miR-675 that suppresses growth and Igf1r. Nat Cell Biol 2012;14:659-665.

57 Wang X, Li Y, Qi W, Zhang N, Sun M, Huo Q Cai C, Lv S, Yang Q: MicroRNA-99a inhibits tumor aggressive phenotypes through regulating HOXA1 in breast cancer cells. Oncotarget 2015;6:32737-32747.

-58 Costa V, Lo Dico A, Rizzo A, Rajata F, Tripodi M, Alessandro R, Conigliaro A: MiR-675-5p supports hypoxia induced epithelial to mesenchymal transition in colon cancer cells. Oncotarget 2017;8:24292-24302. 